\section{Drugs, PPOs, Tiered Cost-Share for Beneficiaries, and Consumer Preferences}

Two-tier copay drug benefit plans have been in existence for nearly 20 years; three-tier copay drug benefit plans emerged at least 10 years ago. PacifiCare of Oklahoma began offering a three-tier copay drug plan in 1992. The most common three-tier drug benefit design at that time required a $\$ 3$ copay for a generic drug, an $\$ 8$ copay for a "formulary" brand drug, and $50 \%$ cost-share for a nonformulary drug, all in a maximum 30-day supply. Ultimately, the three-tier copay drug plan became the predominant form of drug benefit design in the state of Oklahoma, but it took more than two years in the early 1990s for PacifiCare to convince a significant number of employers to adopt the "new" benefit design. Marketing and sales people did not embrace it: "Formularies" and percentage cost-share were "hard to sell."

By 2002, multiple-tier-copay drug benefit plans had become dominant among private employers, HMOs, and other managed care plans. Full choice is one of the valuable features of these three-, four-, and even five-tier drug copay plans. While tiercopays provide financial incentives for use of preferred drugs, members generally have full choice of drugs. Properly administered, tier-copay drug plans obviate the need for online edits that require pharmacist intervention for prior authorization (PA), step therapy, or other administrative controls.

The concept of charging eligible beneficiaries different costshare amounts based upon the cost-effectiveness of the therapy applies beyond prescription drugs. After nearly 10 years of multiple-tier copay plans for prescription drug benefits, PacifiCare Health Systems (Cypress, Calif.) launched its Select Hospitals tiercopay plan in the fall of 2001. Member use of preferred (lowercost) hospitals was associated with $\$ 0$ per day copay, while member use of other, network hospitals had copays of $\$ 100, \$ 250$, or $\$ 400$ per day. ${ }^{1}$ The multiple copayment options by provider were packaged by other health plans in 2002, including Humana in its SmartSuite of options. ${ }^{2}$

As with drug benefit tier-copays, the tiered cost-share method for hospitals is designed to (a) make beneficiaries more aware of the cost differences among alternate therapy choices and (b) encourage the use of lower-cost therapeutic alternatives. HMOs and other managed care plans will likely embrace this tier costshare method for hospitals and physicians, perhaps as enthusiastically as drug benefit managers have done for prescription drugs. The pressure on employers from medical and hospital cost increases that rose dramatically, first in 2000 and for three consecutive years through 2002, make this tier-copay health benefit design a timely addition to managed care.

Health plan members often cite provider choice over many other health plan features as the most important factor when they select a particular health plan, second only to out-of-pocket cost-share amounts. Yet, the survey results are mixed. Health plan members who select IPA-HMOs appear to rate coverage of pharmacy benefits as highly as out-of-pocket cost-share amounts. ${ }^{3}$ Commonly, price factors outweigh quality factors when individual purchasers select a health plan. ${ }^{4}$ In a prescription drug benefit, the drug is probably the metaphor for the provider in the medical portion of the health benefit. In other words, the provider-equivalent in a prescription drug benefit may be the drug itself. Work by Holdford and Carroll in this issue of the Journal supports this notion: "Product choice was the most important attribute in selecting a drug benefit plan."

These results are not surprising; they may even be obvious. Yet the findings of the research by Holdford and Carroll are not generalizable due to several factors, including the higher average income and other atypical characteristics of the study population as well as its small size. The sample size is particularly small compared to the sample sizes typical of marketing surveys. Further, the question is perhaps more complex than it appears. Survey research has suggested an inverse relationship between member knowledge of drug plan coverage and member satisfaction. ${ }^{6}$ Earlier survey research found nearly equivalent member satisfaction in closed formulary (66\%) and open formulary plans (70\%) - a counter-intuitive finding without further examination. Beneath the finding in this earlier research is a subgroup analysis that found the degree of member satisfaction to be related to the absolute amount of the copayment: $71 \%$ of drug plan members were highly satisfied in the $\$ 1$ to $\$ 5$ copay plans (for branded drugs) versus $61 \%$ highly satisfied in drug plans with an $\$ 11$ or higher branded drug copayment. ${ }^{7}$

\section{Adherence, Compliance, and Persistence in Drug Therapy}

Patient compliance with prescribed treatment, adherence to the regimen, and persistence in continuing behavior adherent to therapy are influenced by many factors, including the costs of drug therapy. Patients can measure "cost" in the incidence and severity of side effects as well as the out-of-pocket payment for the drug. White et al. in this issue of the Journal ${ }^{8}$ address the question of the influence of pharmacy provider type, mail service versus community pharmacy, on medication adherence and persistence. As the authors note, this study did not show that mail-service pharmacy has a causal effect on adherence to HMG antilipid therapy. Rather, the authors suggest that users of mail-service pharmacy may be more adherent to HMG therapy. We do not know if the underlying factor is the convenience of mail service, the provision of a 90day supply of medication, or self-selection of mail service versus community pharmacy.

At least two other points are important for readers: (1) This MCO, like many others, owns the mail-service pharmacy, which earns revenue and profit for the enterprise and thereby "competes" with community pharmacies, and (2) The authors did not include the effects of out-of-pocket payments in their research model or statistical analyses of the data. In fact, the authors did not describe precisely the differences in drug benefit design and out-of-pocket costs between the mail-service pharmacy benefit and the community pharmacy benefit. Including variables for out-of-pocket costs 
and the amount of the annual maximum dollar benefit for the Medicare+Choice members in the list of independent variables would have made this research and its results more robust and resistant to alternate explanations for the findings.

Drs. Johnsrud and Schafermeyer ${ }^{9}$ provide a useful review on adherence and persistence in the Subject Reviews section in this issue to help readers interpret the work by White et al. Particularly intriguing in considering methods of improving patient adherence to drug therapy is the complex interaction of severity of disease, number of concomitant drugs used by each patient, and perception of susceptibility. White et al. expressed surprise that mail-service users appeared to be more adherent to HMG drug therapy despite their higher average age and a larger number of co-existing illnesses as measured by the chronic disease score (CDS). It would be equally plausible to hypothesize that these patients would be expected to be more adherent to HMG therapy due to greater perceived susceptibility to adverse outcomes arising from nonadherence. More insight into this question could have been obtained had the authors measured the number of concomitant drugs for each patient and included this measure in their analyses.

\section{Effects of Medicare+Choice Annual Maximum Dollar Prescription Drug Benefits}

About $73 \%$ of Medicare beneficiaries had some form of prescription drug coverage in calendar year $1998,{ }^{10}$ the time period of the study reported by White et al. Medicare HMOs (Medicare+ Choice) plans accounted for about 15\% (about one-fifth of thirdparty coverage) of prescription drug benefits for Medicare beneficiaries in 1998. The share of Medicare+Choice members with prescription drug coverage declined from $84 \%$ in 1999 to $67 \%$ in 2001 , contributing to a decline in the share of prescription drug coverage accounted for by Medicare HMOs to just $10 \%$ of the entire Medicare population in 2001. ${ }^{11}$ Annual dollar maximum limits for Medicare+Choice prescription drug benefits are common, with an average \$1,149 annual maximum limit in 1997 and some as low as $\$ 600$ per year. By 2000, 38\% of Medicare+Choice members with prescription drug benefits had an annual maximum of $\$ 750$ or less.

Data from the Kaiser Family Foundation also show that 13\% of Medicare beneficiaries spent $\$ 2,000$ or more on prescription drugs in 2001, accounting for $52 \%$ of total prescription drug spending for all Medicare beneficiaries. Spending of $\$ 1,000$ or more was found among $28 \%$ of Medicare beneficiaries, equaling $76 \%$ of total expenditures for prescription drugs. Yet an amazing $17 \%$ of Medicare beneficiaries had no (\$0) spending on prescription drugs in 2001. White et al. reported that only 0.01\% (two members) in their Medicare+Choice population exceeded the annual drug benefit maximum, which can be as low as $\$ 500$. They report that $25 \%$ of Medicare beneficiaries in this California HMO had an annual maximum of $\$ 1,000$ or less.

These data are difficult to reconcile. The annual cost of HMG therapy alone could meet or exceed the $\$ 1,000$ annual maximum.
For example, the annual cost of pravastatin, before member copay, was in the range of $\$ 800$ to $\$ 850$ for 1998 and in the range of $\$ 875$ to $\$ 925$ for 1999 . The authors of this study did not measure the incidence or effects of an annual dollar maximum on Medicare member utilization of prescription drugs. They did report that Medicare+Choice members accounted for $56 \%$ of the study subjects in the community pharmacy cohort and $85 \%$ in the mailorder cohort, making these two groups significantly different by this measure.

\section{DUR Messages-Better Data Needed for Making Better Decisions}

Every day, we are bombarded by advertisers competing for the attention of prospective buyers. Marketing messages are everywhere, adding to the blizzard of data that threatens to overload our senses. We struggle to filter information from the noise. Pharmacists are also bombarded at work with electronic alert messages, ranging from requests for preferred drugs to drug-drug interaction messages that could be clinically significant, even lifethreatening, for some patients. There is a real need to increase the ratio of true-positive and clinically significant electronic messages to the total number of messages sent to pharmacists by third-party claims processing systems.

The work by Heaton, Hansten, Martin, et al. ${ }^{12}$ in this issue of the Journal does little to help us cross the quality chasm that exists between what we do today and what we should be doing to improve the quality of care and reduce the incidence of clinically significant, avoidable adverse events attributable to drug interactions. This is yet another report of potential problems in prescription drug therapy. We do not know from this work the number and ratio of drug-interaction alert messages that were communicated to the dispensing pharmacists by the third-party claims processor for these alleged drug-interaction pairs or the pharmacists' responses to these electronic messages.

Drug claim processors have the capability, in the transaction standard (NCPDP version 3.2) that has been effective for more than five years in pharmacy software systems as well as claims processors, to capture information in the claim record regarding electronic messages sent to pharmacies. The current v3.2 electronic claims transaction standard, to be updated and expanded further in version 5.1 for HIPAA compliance later this year, can also capture pharmacist response codes. The authors presumably could have also reported what pharmacists reported as actions taken in response to the drug interaction conflict alert messages. The electronic transaction standard in effect at the time of the study by Heaton et al. permitted at least four response codes: (a) "reason for service code" (e.g., "DD=drug-drug interaction"), (b) "professional service code" (e.g., "M0=prescriber consulted"), (c) "result of service code" (e.g., "1G=filled, with prescriber consulted"), and (d) DUR/PPS level of effort (e.g., how much time was required for the intervention, such as "12=Level 2," indicating 0.25 hours). The presentation of these data would have shed additional light on 
the magnitude of the alleged potential problem associated with apparent dispensing of drug-drug interaction pairs.

The authors do note that they measured no health outcomes in their study. We need better data to permit us to make better decisions to avoid clinically significant drug interactions. Additional perspectives on the path to better data for preventing adverse events caused by drug-drug interactions is provided by Christensen, Fulda, Lyles, and $\mathrm{Pugh}^{13}$ in this issue of the Journal.

Frederic R. Curtiss, Ph.D., R.Ph., CEBS

Editor-in-Chief

\section{REFERENCES}

1. Geisel J. New HMO plans hit higher-cost provider picks. Bus Insurance 2001 (Sept);17:6,12.

2. Anon. Humana program offers wide choice of plans. Bus Insurance 2002 (Mar);25:23.

3. Kertesz L. Standing by their plan-study examines what it takes to build consumer loyalty. Mod Health Care 1998 (Apr);20:108-18.

4. Kazel R. Price often main factor in plan choice: study. Bus Insurance 1996 $(\mathrm{Oct}) ; 21: 6$

5. Holdford D, Carroll NV. Consumer preferences for types of cost containment in prescription drug programs. J Man Care Pharm 2002;8(3):192-98.

6. Anon. Rx satisfaction survey says ignorance is bliss. Man Care Exec Ed 2001 (May):4.

7. Anon. 1998 CareData Commercial Health Plan Member Survey. Man Health Care 1999;(Jun):26.

8. White TJ, Chang E, Leslie S, et al. Patient adherence with HMG reductase inhibitor therapy among users of two types of prescription services. J Man Care Pharm 2002;8(3):186-91.

9. Johnsrud M, Schafermeyer K. Measuring adherence and persistence in drug therapy. J Man Care Pharm 2002;8(3):204-06.

10. Poisal JA, Murray L. Growing differences between Medicare beneficiaries with and without drug coverage. Health Affairs 2001; Mar-Apr;20(2):74-85.

11. Medicare and prescription drugs. The Henry J. Kaiser Family Foundation. 2001; May. www.kff.org

12. Heaton A, Hansten P, Martin S, et al. High frequency of itraconazole prescriptions with potentially interacting medications in a large health care plan. J Man Care Pharm 2002;8(3):199-203.

13. Pugh, M, Christensen D, Fulda T, Lyles A. Better data for making better decisions: Finger-pointing or useful drug use review J Man Care Pharm 2002;8(3):208-10 